\title{
A new device for sampling water from the benthic boundary layer
}

\author{
Ulf Eversberg* \\ Institut für Meereskunde; Düstembrooker Weg 20, D-W-2300 Kiel 1, Germany
}

\begin{abstract}
An instrument is described, which collects water from the benthic boundary layer in shallow waters with a maximum depth of $50 \mathrm{~m}$. Four water samples of 71 each can be collected between $5 \mathrm{~cm}$ and $40 \mathrm{~cm}$ above the sediment. Handling is easy, and the sampling operation is short enough to allow repeated employment even on time-limited, routine investigations. First results show gradients in the organic matter and seston content of samples from the 5 to $35 \mathrm{~cm}$ above the sediment. The oxygen concentrations near the sea bottom decreased faster than those $3 \mathrm{~m}$ above, just below the summer pycnocline.
\end{abstract}

\section{INTRODUCTION}

While knowledge of processes in benthic and pelagic environments has increased quickly in recent years, there is little information concerning processes at the sedimentwater interface. This is partly because there are so few instruments able to sample water close to the sediment. Such samples are necessary to investigate concentrations and composition of particulate material and dissolved material such as nutrients (e.g. Nixon, 1981) or pollutants. Such samples also help to understand the importance of suspension feeding or lateral transport near the sediment (cf. Frithsen \& Doering, 1986; Grant, 1984; Graf, 1987). Water samplers usually employed for this purpose in plankton research are doomed to failure due to their design. Most water samplers, for example the Niskin type, cannot be lowered close to the bottom, and furthermore they sample a range covering the full length of the instrument, i.e. up to $1.5 \mathrm{~m}$.

To obtain water samples from the near-bottom boundary layer, specially designed equipment is necessary. Such equipment must satisfy several conditions:

(1) The water sample must not contain material resuspended through application of the sampler.

(2) The water sample must originate from a defined water layer above the sediment.

(3) The instrument should be small and easy to handle to enable repeated employment during short routine cruises.

The existing near-sediment water samplers (e.g. Tessenow et al., 1977) do not fully meet these requirements. In this paper, a newly constructed device is presented which satisfies the above conditions.

\footnotetext{
- Present address: Meereszoologie, Universität Bremen, Fachbereich 2, Außenstelle: Bürgermeister-Smidt-Straße 20, D-W-2850 Bremerhaven
} 


\section{DESIGN}

The water sampler (Fig. 1) consists of four cylindrical PVC bottles mounted in a boxshaped frame of steel. The frame is assembled on an iron grid with lead weights; this ensures a firm footing on sandy as well as on muddy sediments without any considerable penetration into the substrate. The volume of the bottles is 71 each. Below the bottles PVC tubes are mounted which enlarge to a cone (diameter $8 \mathrm{~cm}$ ) with a $2 \mathrm{~mm}$ wide

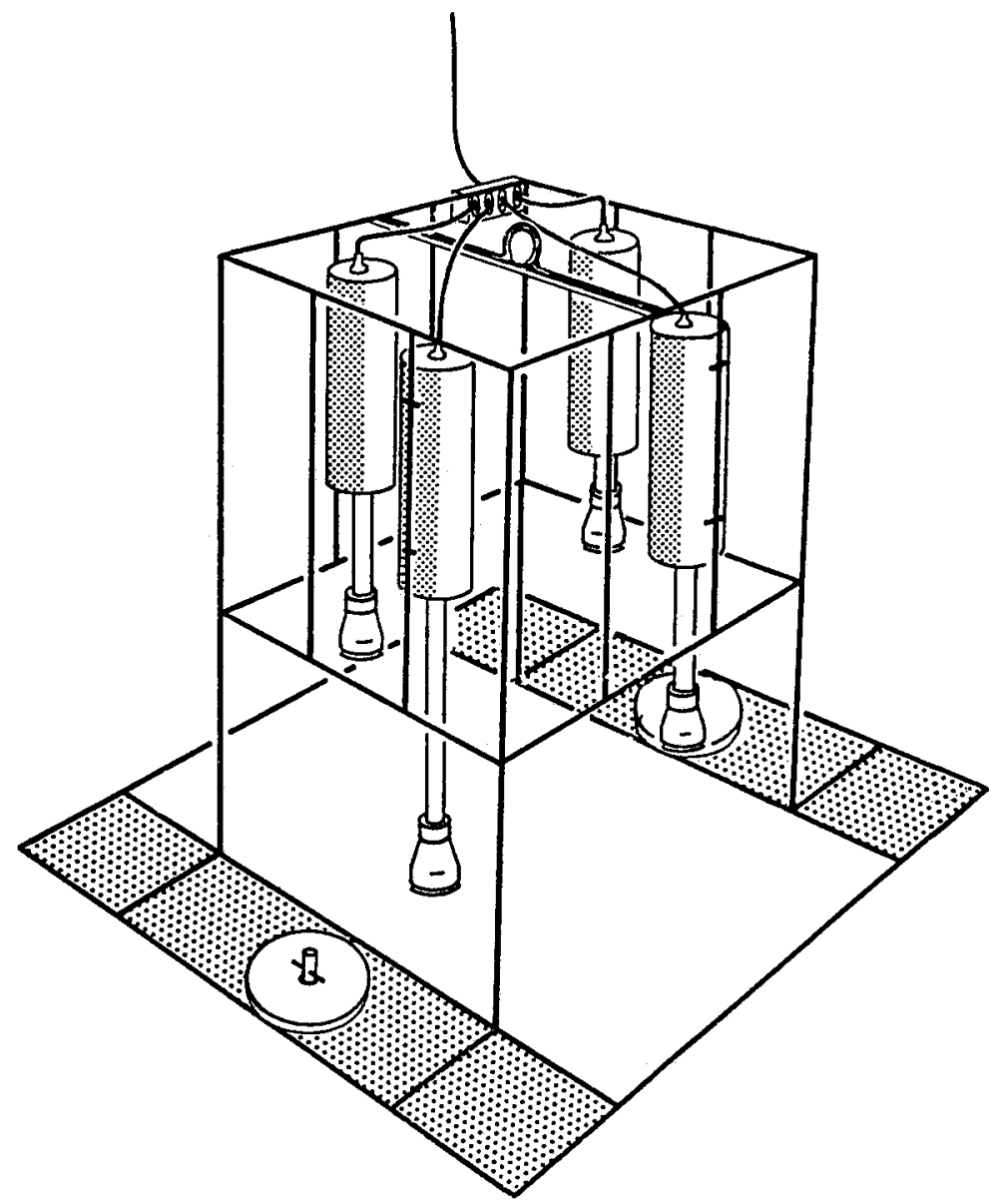

Fig. 1. Steel frame with four PVC water bottles, water inlets at different heights above the ground plate. The hose $(60 \mathrm{~m})$ leads to a nitrogen tank and a safety valve above the surface

horizontal slit as a water inlet (Fig. 2). A ball valve and a tube are located between each bottle and water inlet. The length of the tubing determines the distance between the water inlet and the sediment; the chosen dimensions allow sampling points at $5 \mathrm{~cm}$, $10 \mathrm{~cm}, 20 \mathrm{~cm}$ and $35 \mathrm{~cm}$ above the sediment surface. The water bottles are connected to a pressure resistant hose, $60 \mathrm{~m}$ in length, which leads to a safety valve and a nitrogen tank aboard a vessel. 


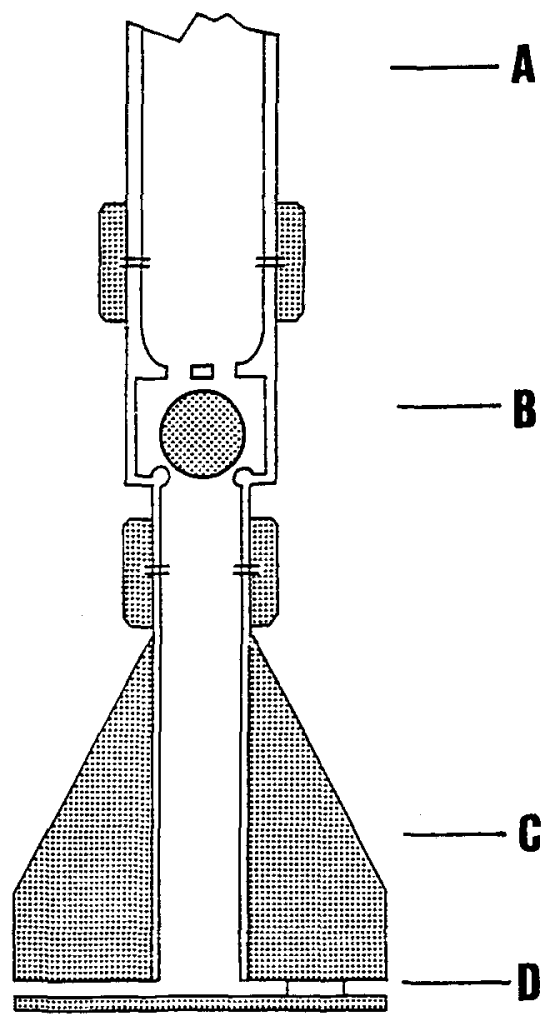

Fig. 2. Schematic drawing of the water inlet and the ball valve. $A=$ tubing; $B=$ ball valve; $C=$ cone; $\mathrm{D}=$ water inlet

On board, the water bottles are filled with nitrogen to a maximum pressure of 6 bar. The ball valves prevent loss of pressure. The sampler is then lowered by cable to the sediment. The hose has to remain slack enough to prevent disturbance by ship movements. Before sampling, a waiting period of some minutes is necessary to allow material resuspended during deployment to drift away with the current. The safety valve is slowly opened on board, resulting in a reduction of gas pressure in the instrument. When the pressure inside the bottles is lower than that outside, the ball valve slowly opens and water flows into the bottles. Once the water bottles are filled, the ball valves will close again by gravitation and the instrument is heaved on board. The water inlet is unscrewed and replaced by a tap with a pin, which will lift the ball from the ball valve.

All parts are tested to a pressure of $10 \mathrm{bar}$; but, for security reasons, the water sampler is used only down to a depth of $50 \mathrm{~m}$. The frame is designed to carry additional instruments, such as current meter and video equipment. 


\section{RESULTS AND DISCUSSION}

The water sampler was tested under various weather conditions at a depth range of $10 \mathrm{~m}$ to $21 \mathrm{~m}$ on sand, sandy-mud and on mud. Usually, after $2.5 \mathrm{~min}$ (max. $4 \mathrm{~min}$ ) no artificially resuspended material was seen with the underwater video system. During sampling (about $5 \mathrm{~min}$ ), no particles were visibly sucked off the sediment surface into the water sampler. Net current speed was continuously low $(\max .2 .5 \mathrm{~cm} / \mathrm{sec}$, measured by an Aandera flowmeter), but some fast horizontal oscillations were observed. These oscillations prevented the use of mono-directional water inlets (Sternberg et al., 1986), because their opening cannot be directed into the flow fast enough by vanes. Assuming the sample (water volume 7 l) derives from a torus around the water inlet (diameter $8 \mathrm{~cm}$ ), the vertical resolution is about $\pm 10 \mathrm{~cm}$ in calm water. With increasing current speed, resolution will be better.

A typical seston and corresponding organic weight profile is shown in Figure 3. Water was collected in May 1987 in Kiel Bight, at $17 \mathrm{~m}$ water depth above a sandy bottom

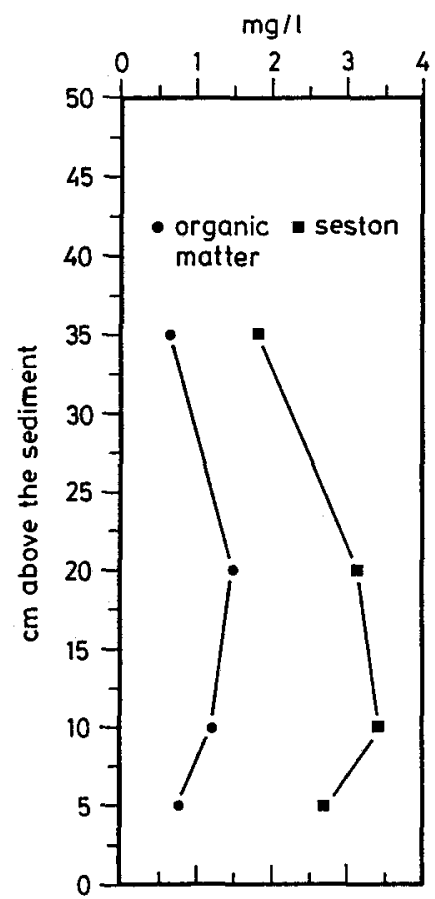

Fig. 3. Seston dry weight and ash free dry weight (Afdw) of water samples at four heights above the sediment of Kiel Bight (water depth $17 \mathrm{~m}$ )

(Gabels Flach). As depicted, there is an increase in seston and in organic weight from $35 \mathrm{~cm}$ above the sediment to $20 \mathrm{~cm}$ above the sediment and a further increase in seston $10 \mathrm{~cm}$ above the sediment. Between $10 \mathrm{~cm}$ and $5 \mathrm{~cm}$, seston concentration and organic weight decrease rapidly.

The oxygen content of water samples at six different dates in 1988 at the station 'Gabels Flach' is shown in Figure 4. Corresponding to the samples near the sediment, 


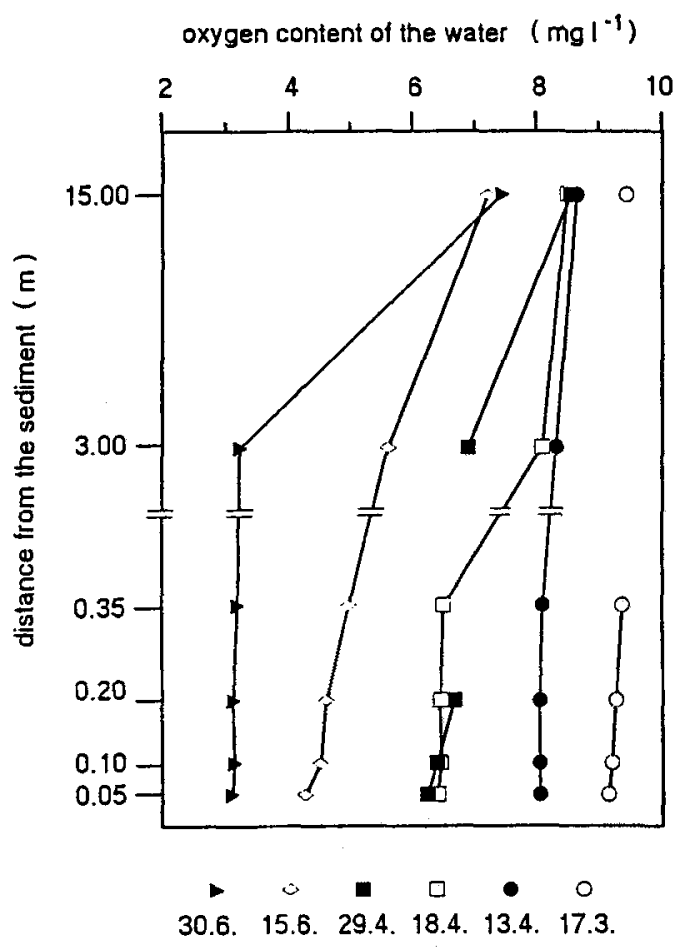

Fig. 4. Six oxygen concentration profiles from 1988. Water samples at four heights in close proximity to the sediment surface, and two additional samples $3 \mathrm{~m}$ and $15 \mathrm{~m}$ above the sediment

oxygen data from the water column $3 \mathrm{~m}$ and $15 \mathrm{~m}$ above the sediment are shown. The data shown in the figure are mean values of three parallels with three measurements each in March and April. The standard error was always less than $5 \%$. In June, only 3 replicates from each sample were measured. While changes of the oxygen concentrations are small near the water surface, there is a fast decrease of the oxygen content near the sediment starting in April. At the end of June, only small amounts of oxygen were found near the seafloor as well as $3 \mathrm{~m}$ above, just below the summer pycnocline. These results suggest that the new equipment promises a better understanding of near bottom processes.

Acknowledgements. I am indebted to W. Queisser, M. Teucher, G. Graf, H. Beese, S. Podewski, K. Reiber and F. Köster.

\section{LITERATURE CITED}

Frithsen, J. B. \& Doering, P. H., 1986. Active enhancement of particle removal from the water column by tentaculate benthic Polychaetes. - Ophelia 25, 169-182.

Graf. G., 1987. Benthic responses to the annual sedimentation patterns. Interactions in coastal waters. Ed. by E. Walger, B. Zeitschel \& J. Rumohr. Springer, Berlin, 84-92.

Grant, J., 1984. Lateral flux of organic matter in the estuarine environment. - Can. tech. Rep. Fish. aquat. Sci. $1263,1-38$. 
Nixon, S. W., 1981. Remineralization and nutrient cycling in coastal marine ecosystems. In: Estuaries and nutrients. Ed. by B. J. Neilson \& L. E. Cronin. Humana Press, Clifton, 111-138.

Stermberg, R. W., Johnson, R. V., Cacchione, D. A. \& Drake, D. E., 1986. An instrument system for monitoring and sampling suspended sediment in the benthic boundary layer. - Mar. Geol. 71, 187-199.

Tessenow, U., Frevert, T., Hofgärtner, W. \& Moser, A., 1977. Ein simultan schließender Serienwasserschöpfer für Sedimentkontaktwasser mit fotoelektrischer Selbstauslösung und fakultativem Sedimentstecher. - Arch. Hydrobiol. (Suppl.) 48, 438-452. 